\title{
Health education to improve repeat participation in the Dutch breast cancer screening programme: evaluation of a leaflet tailored to previous participants
}

\author{
Constance H.C. Drossaert*, Henk Boer, Erwin R. Seydel \\ University of Twente, Department of Psychology, P.O. Box 217, 7500 AE Enschede, The Netherlands
}

Received 10 May 1995; revised 14 March 1996; accepted 19 March 1996

\begin{abstract}
Participation in breast cancer screening programmes often declines in the course of the programme. The purpose of the present study was to examine whether health education could diminish the amount of drop-outs between two screening rounds. The health education was tailored to women who previously underwent mammography. Based on the Elaboration Likelihood Model two versions of the tailored leaflet were made: a simple version and a version with additional peripheral cues. In an experimental study among 2961 women the effects of the tailored leaflets on reparticipation were tested against a standard leaflet. Re-participation rates were high $(>90 \%)$ and did not differ between the 3 groups. No significant differences regarding beliefs about re-participating were found between the 3 groups. Results indicate that the tailored information leaflets did not enhance re-participation. Therefore, the required additional efforts and costs do not seem to be justified. The results of the study provide indications that less painful mammograms and friendly staff might improve re-participation.
\end{abstract}

Keywords: Breast cancer screening; Participation; Health education; Elaboration Likelihood Model

\section{Introduction}

Since 1989 a nationwide breast cancer screening programme has been introduced in the Netherlands. The aim of the programme is to reduce breast cancer mortality by screening every woman between 50 and 69 years with mammography every 2 years. Among other factors like

\footnotetext{
* Corresponding author, Tel.: 3153 4893287; Fax: 3153
} 4892255 . the quality of the screening tests and the incidence rate of breast cancer, participation rate is an important determinant of the success of a screening programme. Only if sufficient women participate in the screening, the aimed reduction in breast cancer mortality will be reached and the screening will be cost-effective [1,2]. In this respect it is important that women participate in the initial screening round and in all subsequent screening rounds. Experimental programmes in The Netherlands have shown a significant decrease in 
participation rates in the course of the screening programme. In the Nijmegen project [3] only $50 \%$ of the women aged 50-64 at the beginning of the programme were still participating in the sixth screening round. Between the first and the second screening round the drop out rate was $17 \%$. In the Utrecht project $[4,5]$ women who did not participate were not invited for subsequent screening. In this project $15-24 \%$ of first round attenders did not re-participate in the second screening round. After 5 screening rounds less than half of the first round attenders still participated in the programme. Significant drop out in subsequent screening rounds is also reported about screening programmes in Sweden [6] and the United States [7].

Many studies have been concerned with finding factors associated with initial participation in breast screening. Factors that have been reported to enhance participation are a younger age [8-13], a higher level of education $[9,13,14]$ and a physician's recommendation $[9,14,15]$. An extended review of factors related to participation in breast screening programmes is provided by Vernon, Laville and Jackson [16]. Only a few studies have examined determinants of long-term participation in breast cancer screening. De Waard et al. [4] found that younger age and having a mother with breast cancer were important determinants of rescreening. Fink et al. [17] also found that younger women were more likely to complete the screening programme.

Besides demographic variables, cognitive determinants like beliefs, attitudes and knowledge have been related to participation $[10,12,15]$. Various social psychological theories can be used to explain the relation between cognitive determinants and health protective behaviour [18-20]. An integrated version of these theories is often used to explain health behaviour $[21,22]$. According to this integrated version, participation in breast cancer screening is influenced by three cognitive determinants: attitude (the weighing of perceived benefits and barriers of participating, including risk perception and outcome expectancies), social norms (the perceived pressure from the environment) and self-efficacy expectations (expectations about one's own capability of participating in the screening). The cognitive determinants are influenced by personal characteristics like health status, age and education level.

The theory predicts that actual performance of the behaviour will lead to a modification of the cognitive determinants. A change in the cognitive determinants might be related to the decline of participation in subsequent screening rounds. In a study of Drossaert et al. [23] the effect of a screening experience with a favourable result on determinants of re-participation was examined. A group of women filled out a questionnaire 6 weeks before initial screening (pre-screening group). A second group of women filled out a questionnaire 6 weeks after their initial screening (post-screening group). In the analysis only women who had actually participated were included. It was found that in general women reported to be very satisfied with the initial breast examination, but some reported pain during mammography or feelings of anxiety. Prior to the initial breast examination women expressed some other cognitions towards screening than after participating in the initial breast examination. Women in the post-screening group felt less susceptible to breast cancer and perceived less pressure from the environment to participate than women in the pre-screening group. In general women in the post-screening group expressed in general higher self-efficacy expectations than women in the pre-screening group.

\subsection{Leaflets tailored to previous participants}

In the Dutch screening programme a standard information leaflet developed by the Dutch Cancer Society is enclosed with every invitation to participate. The standard leaflet contains general information about breast cancer, about the benefits of early detection and about the breast cancer screening programme. Detailed information is provided about the procedures during mammography. Several studies have shown that the leaflet is read by about $60 \%$ of the women $[23,24]$. The standard leaflet is not only sent to women who are invited for an initial mammography, but also to women who are invited for subsequent mammographies. It can be expected that these women are less inclined to read the information leaflet again. In ad- 
dition, women who have already participated in the screening, may have different informational needs than women who are invited for the first mammography. For example, women who had previously undergone mammography will not need extensive information about procedures. A tailored leaflet directed at women who have previously undergone a mammography, may improve the attention paid to the health education and may be an instrument to reduce the amount of drop-outs among previous participants. Although separate health education leaflets for women who previously participated, are relatively cheap compared to other health education methods, it still requires extra efforts and brings extra costs to the screening organizations. The added effect of such tailored leaflets must therefore be closely examined. In the present study a health education leaflet, tailored to women who had previously undergone a mammography, was developed and evaluated.

\subsection{Content of the tailored leaflet}

The content of the tailored leaflet was aimed at establishing or maintaining positive attitudes, positive social norms and high self-efficacy expectations with respect to repeat participation in the screening programme. The information provided in the leaflet was based on findings from previous research on cognitive determinants and initial screening experiences of women in the Dutch breast cancer screening programme [23]. To improve attitude towards repeat participation information was given on the benefits of early detection and the desirability of undergoing repeated mammographies was emphasized. It was explained that despite past favourable screening results women remain susceptible to breast cancer. In order to enhance positive social norms attention was paid to the high participation rate (almost $80 \%$ ) in the first screening round. In order to strengthen selfefficacy expectations, positive first round experiences that were often mentioned by participants (like friendly staff and quick procedures) were brought into memory again, whereas negative experiences (like anxiety and pain) were put in perspective. Emphasized was the research finding that after the initial breast examination for most women the mammography turned out to be much better than expected.

\subsection{Design of the tailored leaflet}

An important factor in the effectiveness of any leaflet is the extent to which the leaflet is read and the information is elaborated. In previous research it was found that the standard information leaflet about breast cancer screening was completely read by only about half of the women [23]. Research by Boer, Seydel and Taal [24] indicated that higher educated women learned more from the standard information leaflet than lower educated women. In order to improve the elaboration of the leaflet tailored to previous participants, special attention was paid to the design of this leaflet. For this aim, we used insights derived from Petty and Cacioppo's Elaboration Likelihood Model [25], which describes how a message can change attitudes. According to the Elaboration Likelihood Model (ELM) attitudes can be changed or adopted by two routes: centrally, by a thoughtful consideration and evaluation of the given information and peripherally, by simply using heuristics or peripheral cues like attractiveness, expert source or number of arguments. According to the theory centrally established attitudes are more enduring, more stable against contra-argumentation and better predictors of behaviour. Therefore, health education should aim at central elaboration of information. The extent to which people are inclined to elaborate centrally is determined by their ability and motivation to elaborate. A person's ability to elaborate is determined by factors like message comprehensibility, time pressure or distraction. The motivation to elaborate is mainly influenced by two factors: personal involvement with the attitude object and a more dispositional 'need for cognition'. According to the Elaboration Likelihood Model, the presence of peripheral cues can thus lead to a change of attitude in two ways: directly by peripheral route, but also indirectly by improving the motivation to elaborate centrally.

Based on this theory, two versions of the tailored leaflet were made and tested: a simple version and an extended version with added 
peripheral cues. The two versions were the same in content, but differed in the way they were designed. The added peripheral cues that were used in the extended version were aimed at improving the attractiveness of the leaflet, by the use of glossy paper, the use of colours (the extended version was remarkably red coloured) and coloured pictures. Secondly the aim was to increase the leaflet's credibility. This was done by including the opinion of an expert (doctor) and an attractive peer group member (elderly women). Photographs of both persons were included in the leaflet. The opinions of these persons were described under the pictures. The doctor stated the importance of reparticipating, while the peer group member was quoted saying that the initial breast examination was far better than she had expected. Finally, the extended version contained strongly opinion holding headlines so that the message was clear by simply scanning the leaflet. In the headlines women were complimented with their previous participation in the programme ('Good that you participated!'). Subsequently it was emphasized that re-participating was important ('Reparticipating is important') and that the organization did their best efforts to make participating as easy as possible for the women ("As easy as possible....'). The simple version of the tailored leaflet was printed in black and white, on cheap paper and contained no photographs or pictures. In this version neutral headlines were used ('If you've participated previously..', 'Why again a mammography?', 'Course of the breast examination').

\subsection{Manipulation check}

To check whether the two experimental leaflets were actually perceived differently, 19 women judged the simple version and 19 women judged the extended version, by a short questionnaire. From Table 1, it can be concluded that the peripheral cues (like expert opinion) are noticed and that the appearance of the extended version is more positively judged than the appearance of the simple version, whereas the content of the leaflets were judged similar by the two groups.

\subsection{Research questions}

In summary the following research questions were examined:
Table 1

Judgement of the simple tailored (ST) and the extended tailored (ET) leaflet

\begin{tabular}{|c|c|c|c|}
\hline \multirow[b]{2}{*}{$\begin{array}{l}\text { Was attention paid to the opinions of } \\
\text { experts? }\end{array}$} & \multicolumn{3}{|c|}{$\begin{array}{l}\text { ST ET P P } \\
n=19 n=19\end{array}$} \\
\hline & 2.7 & 3.7 & 0.001 \\
\hline $\begin{array}{l}\text { Was attention paid to the opinions } \\
\text { of peer group members? }\end{array}$ & 2.8 & 3.3 & n.s. \\
\hline Were the headlines opinion holding? ${ }^{\mathrm{a}}$ & 2.8 & 4.0 & 0.001 \\
\hline \multicolumn{4}{|c|}{ What did you think of the appearance of the leaflet? } \\
\hline ...boring $(-3)$ or interesting $(3) ?$ & 0.2 & 1.2 & 0.01 \\
\hline ...ugly $(-3)$ or beautiful $(3) ?$ & 0.6 & 1.4 & 0.03 \\
\hline $\begin{array}{l}\text {...unattractive }(-3) \text { or attractive } \\
\text { (3)? }\end{array}$ & 0.7 & 1.5 & 0.02 \\
\hline $\begin{array}{l}\text {...hard to read }(-3) \text { or easy to } \\
\text { read (3)? }\end{array}$ & 2.2 & 2.1 & n.s. \\
\hline $\begin{array}{l}\text {...too little }(-3) \text { or too much }(3) \\
\text { text? }\end{array}$ & 0.3 & -0.2 & 0.06 \\
\hline ...nondescript $(-3)$ or striking $(3) ?$ & 0.3 & 0.8 & 0.05 \\
\hline \multicolumn{4}{|c|}{ What did you think of the content of the leaflet? } \\
\hline ...unclear $(-3)$ or clear $(3) ?$ & 2.1 & 2.3 & n.s. \\
\hline ...boring $(-3)$ or interesting (3)? & 1.6 & 1.5 & n.s. \\
\hline ...useless $(-3)$ or useful (3)? & 2.0 & 2.1 & n.s. \\
\hline ...unreliable $(-3)$ or reliable $(3)$ ? & 1.8 & 2.1 & n.s. \\
\hline ...covering (-3) or honest (3)? & 2.3 & 2.1 & n.s. \\
\hline $\begin{array}{l}\text {...discouraging }(-3) \text { or motivating } \\
\text { (3)? }\end{array}$ & 1.5 & 2.0 & 0.04 \\
\hline
\end{tabular}

Differences were tested with Mann-Whitney tests.

${ }^{a} 1=$ definitely not $/ 5=$ definitely yes.

- to what extent can health education tailored to previous participants influence attitude, social norms and self-efficacy expectations regarding reparticipating in the screening programme?

- to what extent can health education tailored to previous participants prevent them from dropping out of the programme?

With respect to the design of the leaflet we expected, in accordance with the Elaboration Likelihood Model, that the extended version would be more effective than the simple version in two ways: (1) by improving women's elaboration likelihood, or (2) by allowing those women with low elaboration likelihood (low personal involvement, low need for cognition or low elaboration abilities) to elaborate peripherally. 


\section{Methods}

\subsection{Setting}

In the Dutch breast cancer screening programme each woman in the age group of 50-69 is invited for a free mammogram every 2 years. The screening programme is financed by the National Health Executive Board (Ziekenfondsraad) and the organisation is performed by 9 regional authorities. The screening is executed in mobile and permanent screening units. Addresses of women in the age group are provided by municipalities. The women are invited for the mammogram by an invitation letter that includes a fixed appointment (day, time, location). The planning of the appointments occurs following postal zip-codes, which implies that women from one street usually are invited the same day. The present study was performed in the region of The Hague, where the second round of the screening programme took place. In The Hague the screening is executed in permanent screening units.

\subsection{Procedures}

During a period of 40 days all women who were invited for their second mammogram, were included for the study $(n=3035)$. The women were assigned to 3 groups, differing in the information leaflet that was enclosed in the invitation (standard, simple tailored or extended tailored). For practical reasons, the assignment to the groups was not completely at random, but was based on the 'planned appointment-day'. Each day was randomly assigned to one of the conditions. This means that all women from one screening day got the same information leaflet (either standard, simple tailored or extended tailored).

To examine re-participation differences between the 3 groups, participation data of all women involved in the study were collected about 3 months after the last planned appointment. The 3 month period allowed for including data of women who had changed their appointment as well. Women who had cancelled their appointment because of legitimate reasons (e.g. already had a mammogram on their own) were excluded from analysis. During one of the study days, there was a technical defect in the screening unit, so that all women had to be rescheduled. Because the participation of that day was seriously disturbed by this event, we excluded all women of that specific day from the analyses as well. This left a sample of 2961 women eligible for second screening.

Questionnaires were sent to a random sample of about $50 \%$ of each of the 3 groups. The questionnaires were sent a few days after the women had received their invitation but before the mammography was scheduled. To make sure that women filled out their questionnaires before participating in the screening, women were asked to bring their filled out questionnaires to the screening unit. If a woman did not intend to participate, she was asked to return her questionnaire by mail in a prepaid answering envelope. In total 1392 questionnaires were sent; $963(70 \%)$ filled-out questionnaires were returned. Response rates were, respectively $67 \%$ for those with the standard leaflet, $69 \%$ for those with the simple tailored version and $71 \%$ for those with the extended tailored version.

\subsection{Operationalisations}

The questionnaires contained questions about sociodemographic variables, reading of the leaflet, cognitive determinants of re-participating, variables derived from the Elaboration Likelihood Model and experiences with initial screening.

\subsubsection{Sociodemographic variables and reading of leaflet}

Demographic characteristics included age, education and marital status. With respect to the reading of the leaflet women were asked to what extent they had read the leaflet $(1=$ not at all... $5=$ studied thoroughly) and whether or not they read it immediately after they received it.

\subsubsection{Psychosocial determinants of re-participation}

Participation intention was measured by computing the mean score on two items $(r=0.88)$ regarding participating in the present screening round and participating in all subsequent screening rounds. Answering options for both items ranged from $(-2=$ strongly intend not to participate... 2 = strongly intend to participate). Attitude 
was measured globally with one question ('For me participating is good (2)... bad (-2)') and more specifically by means of 8 items concerning positive and negative outcomes of participating in the screening programme. An example of an item is: 'A breast examination is damaging to my breasts' with answering options: 'fully disagree (1)... fully agree (5)'. Because the internal consistency of the 8 items was not high $(\alpha=0.47)$, the items were analyzed separately. Social norms were measured globally with 1 item ('In general most people in my environment think that I certainly should (2)... should not (-2) participate') and more specifically by means of normative beliefs of six referents and the motivations to comply to the opinion of the referents. An example of a normative belief question is: 'My partner thinks that I certainly should (2)... should not (-2) participate'. An example of a motivation to comply-question is: 'When it comes to early detection behaviour I do strongly (3)... do not (0) comply to the opinion of my partner'. Specific subjective norm score was computed by the mean of the products of normative beliefs and motivation to comply ( $\alpha=0.78$ ). Self-efficacy was measured globally by one item ('I am definitely able (2).... not able (-2) to participate on the coming screening round') and more specifically by a 7 -item scale $(\alpha=0.75)$ about different practical and psychological barriers to screening. An example of an item is: 'For me, getting to the screening unit is very difficult (1)... not difficult (4)'.

\subsubsection{Variables derived from the Elaboration Likelihood Model}

Ability to elaborate was measured with a 4-item scale $(\alpha=0.83)$ measuring the efforts it usually takes to read leaflets about health. Examples of items are: 'It usually takes me no effort to make time to read leaflets about health' and 'Health education leaflets always contain words that I do not understand'. Women were asked to indicate on a 5-point scale the extent to which they agreed with the statements. Personal involvement was measured with a 6-item scale $(\alpha=0.83)$ containing items about involvement with breast cancer and breast cancer screening. Examples of items are: 'I feel involved with the breast cancer screening programme', 'When I see an article about breast cancer I always read it', 'I'm interested in things that deal with breast cancer or breast cancer screening'. Women were asked to indicate on a 5point scale the extent to which they agreed with the statements. Need for cognition was measured with a shortened version of the Dutch translation of Petty and Cacioppo's need for cognition scale $[26,27]$. The 4 items with the highest item-total correlations $(>0.6)$ were included. A fifth item was added: 'When I have to make a decision I always carefully weigh pros and cons against each other'. Cronbach's alpha for this scale was 0.55 .

\subsubsection{Experiences with initial screening}

The questionnaire included questions on general satisfaction about previous screening $(1=$ very unsatisfied ... $4=$ very satisfied), about treatment by staff $(-2=$ felt poorly treated... $2=$ felt well treated), about the travelling time to reach the unit $(1=<15 \min . . .4=>60 \mathrm{~min})$, satisfaction about the distance to the unit (too far/not too far) and waiting time ( $(=$ no waiting time... $4=>30 \mathrm{~min})$. Further, women were asked to indicate the extent to which the mammogram had caused distress ( $1=$ not... $4=$ very $)$ or pain $(1=$ not... $4=$ very $)$ and the duration of pain ( $1=$ immediately disappeared... $4=$ lasted for longer than a day).

\subsection{Statistical analysis}

To examine the extent to which the tailored information had effect on re-participation and intermediating variables, participation data and data from the questionnaires of those with the simple tailored leaflet as well as of those with the extended tailored leaflet were pairwise compared to the data of those with the standard leaflet. To investigate the effect of the leaflet's design, 'comparisons were made between the two experimental groups (simple tailored vs. extended tailored). Differences were tested with $\chi^{2}$-tests (for dichotomous variables) or analysis of variance. Multivariate analysis of variance (MANOVA) was used when appropriate. When multivariate differences were established, additional univariate comparisons (ANOVA) were made. Differences in sociodemographics were controlled by including these variables as covariates. 


\section{Results}

\subsection{Sociodemographic variables and reading of leaflet}

Despite the random assignment to the conditions, some differences in sociodemographics between the 3 groups existed (see Table 2). Women with the simple tailored leaflet were higher educated and more often single than women from the two other groups. Women who received the simple tailored leaflet were significantly older than the women who received standard leaflet. To control for these background differences, age, education and having a partner were included as covariates in the analyses of variance. Regarding the use of the leaflet it was found that those who received the simple tailored leaflet had been reading the leaflet significantly more thoroughly than those who received the standard leaflet or the extended tailored leaflet (Table 3). The differences remained significant when controlled for differences in age and education.

\subsection{Cognitive determinants of re-participation}

In general women were very positive about reparticipating in the screening programme: attitudes, social norms, self-efficacy expectations and intentions regarding re-participating were all very positive (see Table 4). Multivariate analysis of var-

Table 2

Sociodemographics of those who received the standard leaflet (S), the simple tailored leaflet (ST) or the extended tailored leaflet (ET)

\begin{tabular}{llllllll}
\hline & $\begin{array}{l}\text { S } \\
n=296\end{array}$ & $\begin{array}{l}\text { ST } \\
n=309\end{array}$ & $\begin{array}{l}\text { ET } \\
n=305\end{array}$ & $\begin{array}{l}\text { S vs. } \\
\text { ST }\end{array}$ & $\begin{array}{l}\text { S vs. } \\
\text { ET }\end{array}$ & $\begin{array}{l}\text { ST vs. } \\
\text { ET }\end{array}$ \\
\hline $\begin{array}{l}\text { Education } \\
\begin{array}{l}(1 / 3)^{1} \\
\text { Age }\end{array}\end{array}$ & 1.61 & 1.77 & 1.65 & 0.00 & n.s. & 0.02 \\
$\begin{array}{l}\text { Marital status } \\
\text { (\% living } \\
\text { with }\end{array}$ & 60.7 & 61.6 & 61.1 & 0.04 & n.s. & n.s. \\
partner) $^{2}$ & & 62.3 & 70.4 & 0.09 & n.s. & 0.08 \\
\hline
\end{tabular}

${ }^{1}$ Differences were tested with $F$-tests.

${ }^{2}$ Differences were tested with $\chi^{2}$-tests.
Table 3

The extent to which the standard leaflet (S), the simple tailored leaflet (ST) and the extended tailored leaflet (ET) were read

\begin{tabular}{lrrr}
\hline Did you read the leaflet? & S & ST & ET \\
\hline Not at all & $7 \%$ & $6 \%$ & $8 \%$ \\
Glanced at it & $11 \%$ & $9 \%$ & $12 \%$ \\
Have read some parts & $13 \%$ & $9 \%$ & $11 \%$ \\
Read it completely & $64 \%$ & $63 \%$ & $65 \%$ \\
Studied it thoroughly & $5 \%$ & $4 \%$ & $4 \%$ \\
\hline
\end{tabular}

iance revealed that the mean scores of women who got the simple tailored version differed significantly from the mean scores of women with the standard leaflet $\left(F_{\text {muttiv. }}(7,466)=2.3, P=0.03\right)$. Univariate analysis revealed that this difference was predominantly caused by differences in specific social norms. Women with the standard leaflet perceived significantly less social pressure to participate than women with the simple tailored leaflet. No significant multivariate differences in cognitive determinants were found between the group receiving the standard leaflet and the group receiving the extended tailored leaflet $\left(F_{\text {multiv. }}(7,468)=\right.$ 0.7 , n.s.), nor were differences found between the simple and the extended version of the tailored leaflet $\left(F_{\text {multiv. }}(7,467)=1.2\right.$, n.s.). Even when considering only women that have been reading the leaflet (that indicated to have read the leaflet completely), no significant differences in behavioural determinants were found between the standard leaflet and the simple tailored version $\left(F_{\text {multiv. }}(7,343)=1.8, P=\right.$ n.s. $)$, between the standard leaflet and the extended tailored version $\left(F_{\text {multiv. }}(7,321)=0.58, P=\right.$ n.s. $)$, nor between the two versions of the tailored leaflet $\left(F_{\text {multiv. }}(7,351)\right.$ $=0.64, P=$ n.s.).

\subsection{Second round participation}

The actual second round participation rates were $89 \%(912 / 1026)$ for the standard leaflet group, $90 \%$ (941/1044) for the group that got the simple tailored leaflet and $90 \%(802 / 891)$ for the group that got the extended tailored leaflet. Pairwise $\chi^{2}$-tests revealed no significant differences between any combination of groups. 
Table 4

Mean scores on determinants of re-participating and $P$-values for differences between groups receiving the standard leaflet (S), the simple tailored leaflet (ST) or the extended tailored leaflet (ET)

\begin{tabular}{lllllll}
\hline & $\mathrm{S} n=297$ & $\mathrm{ST} n=311$ & $\mathrm{ET} n=310$ & $\mathrm{~S}$ vs. ST & $\mathrm{S}$ vs. ET & ST vs. ET \\
\hline Global attitude $(-2 /+2)$ & 1.9 & 1.9 & 1.8 & n.s. & n.s. & n.s. \\
Global social norms $(-2 /+2)$ & 1.5 & 1.4 & 1.3 & n.s. & n.s. & n.s. \\
Specific social norms $(-6 /+6)$ & 2.4 & 2.7 & 2.4 & 0.001 & n.s. & 0.012 \\
Global self-efficacy $(-2 /+2)$ & 1.7 & 1.8 & 1.7 & n.s. & n.s. & n.s. \\
Specific self-efficacy $(1 / 4)$ & 3.8 & 3.8 & 3.8 & n.s. & n.s. & n.s. \\
Intention present round $(-2 /+2)$ & 1.9 & 1.9 & 1.9 & n.s. & n.s. & n.s. \\
Intention future rounds $(-2 /+2)$ & 1.8 & 1.8 & 1.8 & n.s. & n.s. & n.s. \\
\hline
\end{tabular}

All differences were tested with $F$-tests.

\subsection{Differences between participants and non- participants}

Only 36 women filled out a questionnaire, but did not participate in the screening programme. The data of these 'drop-outs' were compared to the data of the 'adherers'. As could be expected, drop-outs had significantly lower scores on attitude $(F(1,903)=101.8, P<0.001)$, perceived less social pressure to participate $(F(1,875)=9.3$, $P=0.002$ ), and had significantly lower scores on self-efficacy $(F(1,897)=127.8, P<0.001)$ compared to adherers. No significant differences between drop-outs and adherers were found regarding education and age. A remarkable finding was that drop-outs and adherers had been reading the leaflet to the same extent.

Drop-outs were in general significantly less satisfied $(F(1,897)=32.4, P<0.001)$ about their initial breast examination than adherers. In comparison to adherers drop-outs had experienced more pain $(F(1,899)=14.0, P=0.001)$, considered the pain to have lasted longer $(F(1,724)=26.8, P<0.001)$ and felt to be less well treated by the staff $(F(1,898)=13.0, P<0.001)$.

\subsection{Effects of design of the leaflets}

We expected that the leaflet with the added peripheral cues would improve women's motivation to elaborate the leaflet by enhancing personal involvement with breast cancer screening. This ex- pectation was not supported. Those who received the extended version of the tailored leaflet reported even less personal involvement than those who received the simple version of the leaflet $(F(1,566)=3.8, P=0.05)$.

Our second expectation was that among those with low elaboration likelihood, the leaflet with the added peripheral cues would promote peripheral attitude change. To test this we examined whether effects of the leaflet's design could be established in subgroups that according to the Elaboration Likelihood Model can be regarded as 'peripheral elaborators'. Within the groups that scored low (under the 33rd percentile) on ability, personal involvement and need for cognition, differences in cognitive determinants between the two versions were examined. The mean scores are presented in Table 5. Multivariate analyses did not reveal significant effects of the design (simple vs. extended) within the low ability group $\left(F_{\text {multiv }}(8,135)=1.17\right.$, n.s. $)$, within the low personal involvement group $\left(F_{\text {multiv }}(8,201)<1\right.$, n.s. $)$, nor within the low need for cognition group $\left(F_{\text {multiv }}(8,163)<1\right.$, n.s. $)$.

\section{Conclusions}

For the success of a breast cancer screening programme, it is important that as many women as possible participate and keep participating in the programme. However, different studies have shown that participation rates often decline in the 
Table 5

Differences in mean scores on determinants of re-participation between women receiving the simple version and women receiving the extended version of the tailored leaflet. In the analysis only women were included with low personal involvement, low need for cognition and low elaboration abilities

\begin{tabular}{|c|c|c|c|c|c|c|}
\hline & \multicolumn{2}{|c|}{ Low involved } & \multicolumn{2}{|c|}{ Low need for cognition } & \multicolumn{2}{|c|}{ Low elaboration abilities } \\
\hline & ST $n=105$ & ET $n=115$ & ST $n=91$ & ET $n=83$ & ST $n=91$ & ET $n=100$ \\
\hline Has read leaflet $(1 / 5)$ & 3.4 & 3.2 & 3.5 & 3.4 & 3.4 & 3.5 \\
\hline Global attitude $(-2 / 2)$ & 1.8 & 1.7 & 1.8 & 1.9 & 1.9 & 1.9 \\
\hline Global social norms $(-2 / 2)$ & 1.2 & 1.3 & 1.3 & 1.3 & 1.4 & 1.3 \\
\hline Specific social norms $(-6 / 6)$ & 2.1 & 2.0 & 2.8 & 2.4 & 3.0 & 2.5 \\
\hline Global self-efficacy $(-2 / 2)$ & 1.7 & 1.6 & 1.8 & 1.7 & 1.9 & 1.6 \\
\hline Specific self-efficacy $(1 / 4)$ & 3.8 & 3.8 & 3.8 & 3.7 & 3.8 & 3.8 \\
\hline Intention towards present round $(-2 / 2)$ & 1.9 & 1.8 & 1.9 & 1.9 & 2.0 & 1.9 \\
\hline Intention towards future rounds $(-2 / 2)$ & 1.8 & 1.6 & 1.8 & 1.9 & 1.9 & 1.8 \\
\hline
\end{tabular}

${ }^{*} P<0.05(F$-test $)$

course of a screening programme. Health education tailored to women who previously underwent mammography might be an instrument to reduce the amount of women that drop out of the programme. In the present study two versions of a tailored health education leaflet were developed: a version with a simple design and a version with added peripheral cues. In a field-experiment, involving 2961 women who were invited for their second mammogram, the effects of the two versions of the tailored leaflet were compared to the effects of a standard leaflet. Actual second round participation data as well as survey data on beliefs about re-participating were used as evaluation criteria.

Results revealed that the second round participation rate was high ( $>90 \%$ ) in all 3 groups. Between the group who got the standard leaflet and the groups who got either version of the tailored leaflet, no significant differences were found with regard to actual re-participation rates, nor with regard to beliefs about re-participating. The tailoring of information to women who previously underwent mammography did not reduce the amount of drop-outs between two screening rounds.

The drop out rate was less than $10 \%$, which is a lower rate than was a priori expected based on results of experimental projects in the Netherlands [3,4]. A possible explanation for the lower drop out rate in this study could be a questionnaire effect, which means that women who received the questionnaire felt obliged to participate. The finding that participation rates in women who did receive a questionnaire were not different from participation rates in women who did not receive a questionnaire, does not support this explanation. Although no effects of the tailored leaflets on reparticipation rates could be established in the present study with a drop out rate of $10 \%$, tailoring health education to women who previously underwent mammography may be effective in screening programmes with higher drop out rates.

The drop-out percentage of $10 \%$ is not too high, but it must be taken into account that research has indicated that drop outs after the first screening round do to a large extent never participate in the screening programme again [28]. Therefore, efforts to minimize the amount of drop-outs must be continued. Results from this study have indicated that first round screening experiences play an important role in the decision to re-participate: dropouts felt less well-treated by the staff during their first mammogram and considered their first mammogram to be significantly more painful compared to adherers. To enhance repeat participation customer service in the screening units should remain optimal and painful mammography should be avoided.

One of the aims of our study was to examine 
whether the design of the health education material could make the material more accessible to women. For this aim, based on the Elaboration Likelihood Model, two versions of the tailored leaflet were made: a simple version and an extended version with added peripheral cues. According to the Elaboration Likelihood Model the added peripheral cues would encourage elaboration likelihood (by increasing personal involvement) or allow peripheral elaboration among those with low elaboration likelihood. The results revealed that overall there were no differences between the two versions. The added peripheral cues did not increase personal involvement, nor were there indications of peripheral attitude change among those with low involvement, low need for cognition or low elaboration ability. These results must however be interpreted in the light of the high general re-participation rates, which make it very difficult to establish any effects. Another possible explanation for the lack of effect of design of the leaflet, might be that the women could all be regarded as highly involved since they already have participated in the first round of the screening programme. The findings that involvement had a very wide range and the fact that a relatively large group did not completely read the leaflet, do not subscribe to this explanation. It was found that those who received the simple version had been reading the leaflet even more extensively than those who received the extended version. Possibly the use of colours and pictures distracted from the content instead of attracted to it. More research regarding the practical usefulness of Elaboration Likelihood Model in designing health education leaflets is desirable.

Practical implications from this study are that drop out in breast cancer screening programmes cannot be prevented by a leaflet tailored to women who previously underwent mammography. It is possible that health education by leaflets is too weak an intervention to influence re-participation behaviour in women who already have screening experiences. Because leaflets are however relatively cheap and can be easily used in mass screening for breast cancer, in this study the possible effects of health education by means of leaflets were examined. Whether more intensive educational ef- forts (like health education in groups or personal health education) about re-participation in breast cancer screening would be more effective, is an empirical question at this time. Results from this study indicate that service quality during mammography might be an important determinant of re-participation.

\section{Acknowledgements}

This research was financed by the Dutch Cancer Society. We kindly thank the 'Stichting Kankerpreventie West-Nederland' in Leyden for their cooperation in this study.

\section{References}

[1] Ineveld BM, van Ootmarssen GJ, Koning HJ, Boer R, van der Maas PJ. How cost-effective is breast cancer screening in different EC countries? Eur J Cancer 1993; 29: $1663-1668$.

[2] Beemsterboer PMM, de Koning HJ, Warmerdam PG, Boer R, Swart E, Dierks ML, Robra BP. Prediction of the effects and costs of breast cancer screening in Germany. Int J Cancer 1994; 58: 623-628.

[3] Peeters PHM, Verbeek ALM, Hendriks JHCL, van Bon MJH. Screening for Breast Cancer in Nijmegen. Report of six screening rounds. In: The extent of side-effects in screening for breast cancer. Dissertation, Nijmegen, 1989.

[4] De Waard F, Colette HJA, Rombach JJ, Baanders-van Halewijn EA, Honing C. The DOM project for the Early Detection of Breast Cancer, Utrecht, The Netherlands. J Chron Dis 1984; 37: 1-44.

[5] De Waard F, Colette HJA, Rombach JJ, Baanders-van Halewijn EA, Honing C. Bevolkingsonderzoek op Borstkanker, een terugblik op het DOM-project. (Mass screening for breast cancer, review of the DOM-project). Gezondheid en Samenleving 1987; 8: 167-173.

[6] Tabar L, Fagerberg G, Duffy SW, Day NE. The Swedish two county trial of mammographic screening for breast cancer: recent results and calculation of benefit. J Epidemiol Comm Health 1989; 43: 107-114.

[7] Baker LH. Breast cancer detection demonstration project: five year summary report. CA-A Cancer J Clin 1982; 32: 194-225.

[8] Owens GR, Daly J, Heron K, Leinster SJ. Psychological and social characteristics of attenders for breast screening. Psychol Health 1987; 1: 303-313.

[9] Maclean UD, Sinfield D, KJein S, Harnden B. Women who decline breast screening. I Epidemiol Comm Health 1984; 38: 278 -283.

[10] Calnan $M$. The health belief model and participation in 
programmes for the early detection of breast cancer: a comparative analysis. Soc Sci Med 1984; 19: 823-830.

[11] Eardley A, Elkind A. A pilot study of attendance for breast cancer screening. Soc Sci Med 1990; 30; 693-699.

[12] Hobbs P, Smith A, George WD, Selwood RA. Acceptors and rejectors of an invitation to undergo breast screening compared to those who referred themselves. J Epidemiol Comm Health 1980; 34: 19-22.

[13] Rutledge DN, Hartman WH, Kinman PO, Winfield AC. Exploration of factors affecting mammography behaviors. Prev Med 1988; 17: 412-422.

[14] Fink R, Shapiro S, Lewison J. The reluctant participant in a breast cancer screening progran. Public Health Rep 1968; 83: 479-490.

[15] Rimer BK, Kasper Keintz M, Kessler HB, Engstrom PF. Why women resist screening mammography: patientrelated barriers. Radiology 1989; 172: 243-246.

[16] Vernon SW, Laville EA, Jackson GL. Participation in breast screening programs: a review. Soc Sci Med 1990; 30: 1107-1118.

[17] Fink R, Shapiro S, Roester R. Impact of efforts to increase participation in repetitive screenings for early breast cancer detection. Am J Public Health 1972; 62: 328-336.

[18] Fishbein M, Ajzen I. Belief attitude intention and behaviour; an introduction to theory and research. Reading MA: Addison Wesley, 1975.

[19] Bandura A. Self-efficacy mechanism in psychosociological activation and health promoting behaviour. In: Madden IV J, Mathysse S, Barchas J, editors. Adaptation, learning and affect. New York: Raven Press, 1986.

[20] Janz NK, Becker MH. The Health Belief Model: a decade later. Health Educ Q 1984; 11: 1-47.

[21] De Vries H, Dijkstra M, Kuhlman P. Self-efficacy, the third factor besides attitude and subjective norm as a predictor of behavioural intentions. Health Educ Res 1988; 3: 273-282.

[22] De Vries H, Backbier E, Kok G, Dijkstra M. The impact of social influences in the context of attitude, selfefficacy, intention and previous behaviour as predictors of smoking onset. J Appl Soc Psych 1995; 25: 237-257.

[23] Drossaert CHC, Boer H, Seydel ER. Geen aanwijzingen voor borstkanker gevonden: De effecten van een negatieve screeningsuitslag na het bevolkingsonderzoek borstkanker op particpatie-bereidheid en patient-delay (No indications for breast cancer: the effects of a favourable screening result after participating in breast cancer screening on re-participation intention and patient delay). Aspekt 37. Enschede: Universiteit Twente, Vakgroep Psychologie, 1992.

[24] Boer H, Seydel ER, Taal E. Knowledge gap effects in health education on mass screening with mammography. In: Dauwalder JP, editor. Psychology and Promotion of Health. Bern: Hogrefe \& Huber, 1994.

[25] Petty RE, Cacioppo JT. The Elaboration Likelihood Model of persuasion. In: Berkowitz, editor. Advances in Experimental Social Psychology, Vol. 18. New York: Academic Press, 1986.

[26] Cacioppo JY, Petty RE. The need for cognition. J Pers Soc Psych 1982; 47: 116-131.

[27] Pieters RGM, Verplanken B, Modde JM. Neiging tot nadenken: Samenhang met beredeneerd gedrag. (Need for cognition: correlation with reasoned behaviour). Ned Tijdschr Psych 1987: 42: 62-70.

[28] Scaf-KJomp W, Van den Heuvel WJA. Participatie in retrospectief (Participation in retrospective). Groningen: Noordelijk Centrum voor Gezondheidsvraagstukken, 1993. 